\title{
The vasodilator stress ECG: Should depression cause anxiety?
}

\author{
Brian G. Abbott, MD, FACC, FASNC, FAHA
}

\section{See related article, pp. 84-91}

For more than a century, the resting electrocardiogram (ECG) has endured as the cornerstone in the diagnosis of cardiac disease. The information provided from the modern day version of Einthoven's string galvanometer ${ }^{1}$ remains at times more useful than other more sophisticated technology, as evidenced by its central role in the management of acute chest pain, with the decision to pursue a reperfusion strategy based almost exclusively on the presence of diagnostic ECG findings. ${ }^{2}$ The ECG also provides us with important information regarding the potential presence of coronary artery disease (CAD) and ischemia when interpreted during exercise and pharmacologic stress testing. While a very sensitive instrument, it suffers from a lack of specificity and consequent false positive results. As newer modalities to assess myocardial ischemia with imaging have evolved, diagnostic accuracy has increased, and many studies have demonstrated that imaging adds both incremental diagnostic and prognostic information to that predicted by the clinical data and ECG alone. ${ }^{3}$ Ischemic ECG changes during exercise stress testing have been demonstrated to provide additional prognostic information in the setting of perfusion abnormalities, but considered as "false-positive", when perfusion images are normal., Similar to exercise stress, stress ECG changes during pharmacologic stress can also be important. However, the diagnostic and prognostic significance of vasodilatorinduced ischemic ECG changes in the setting of normal perfusion is less certain, as previous studies of this unique finding have demonstrated discordant results. ${ }^{6-9}$

In this issue of the Journal of Nuclear Cardiology, Azemi et al ${ }^{10}$ from Hartford Hospital and the University of Connecticut, School of Medicine provide us with further insight into the clinical implications of ischemic ECG changes during vasodilator stress. In a retrospective

From the Rhode Island Hospital, Brown University, Providence, RI. Reprint requests: Brian G. Abbott, MD, FACC, FASNC, FAHA, Rhode Island Hospital, Brown University, Providence, RI; babbott@lifespan.org.

J Nucl Cardiol 2012;19:13-5.

$1071-3581 / \$ 34.00$

Copyright $@ 2011$ American Society of Nuclear Cardiology.

doi:10.1007/s12350-011-9478-5 analysis of more than 5,000 patients undergoing pharmacologic stress myocardial perfusion imaging (MPI) with either dipyridamole or adenosine over a 14-year period, the authors identified a diagnostic cohort of 622 patients with no prior history of myocardial infarction (MI) or coronary artery bypass surgery (CABG) and no baseline ECG abnormalities who underwent coronary angiography within 90 days of MPI. Another 3,566 patients with no history of prior $\mathrm{MI}$ or $\mathrm{CABG}$ and without baseline ECG abnormalities who underwent vasodilator stress served as a prognostic cohort, with a mean follow-up of two and half years evaluating for cardiac death and nonfatal MI. The presence of STsegment depression during vasodilator stress ECG changes was associated with an increased incidence of significant CAD in patients with concomitant perfusion abnormalities, but not in patients with normal perfusion images. When evaluating all patients in the study, ischemic ECG changes were not predictive of outcome, regardless of the MPI result. The authors conclude that the presence of ECG changes with vasodilator stress is of minimal diagnostic or prognostic significance.

This study adds to a growing body of literature that has focused on furthering our understanding of the role of the stress ECG during vasodilator stress. Previous reports have varied in terms of inclusion criteria, and patient selection with respect to $\mathrm{MI}$ or $\mathrm{CABG}$, exclusion of baseline ECG abnormalities, and the type of vasodilator stress agent(s) used. Table 1 summarizes the present study findings along with prior studies which have evaluated this observation with respect to associated impact on outcomes. One notable difference is that studies that included patients with known CAD, prior MI, and/or revascularization tended to find a higher adverse cardiac event rate during follow-up. Interestingly, while discordant in other aspects, a recurrent and rather provocative theme in all these studies is the much higher incidence of ST-segment depression with normal MPI in women than in men. Almost every study evaluating the significance of vasodilator stress ECG changes in association with normal MPI has found that that $\geq 80 \%$ of the patients with this finding were women.

As noted by the authors, the high rate of CAD (30\%-40\%) found on catheterization in the diagnostic cohort was likely driven by referral bias, in that patients referred for angiography with normal perfusion were 
Table 1. Summary of studies evaluating outcomes in patients with vasodilator stress ECG changes and normal MPI

\begin{tabular}{|c|c|c|c|c|c|c|c|c|}
\hline & $\begin{array}{l}\text { Azemi } \\
\text { et al }{ }^{10}\end{array}$ & $\begin{array}{c}\text { Hage } \\
\text { et al }\end{array}$ & $\begin{array}{l}\text { Hage } \\
\text { et } \mathbf{a l}^{8}\end{array}$ & $\begin{array}{c}\text { Sharma } \\
\text { et } \mathbf{a l}^{\text {9 }}\end{array}$ & $\begin{array}{l}\text { Chow } \\
\text { et al }\end{array}$ & $\begin{array}{l}\text { Abbott } \\
\text { et } \mathbf{a l}^{6}\end{array}$ & $\begin{array}{c}\text { Klodas } \\
\text { et } \mathbf{a l}^{7}\end{array}$ & $\begin{array}{c}\text { Uthamalingam } \\
\text { et }^{1 l^{13 *}}\end{array}$ \\
\hline $\mathrm{N}$ & 130 & 73 & 65 & 76 & 72 & 66 & 49 & 43 \\
\hline$\%$ Cohort & 5 & CBD & 1.2 & 2 & 11 & 2 & 0.9 & 1.7 \\
\hline Stressor & Dipy/Adeno & Adeno & Adeno & Adeno & Dipy & Adeno & Adeno/Dipy & Rega \\
\hline $\begin{array}{l}\text { CAD } \\
\text { excluded }\end{array}$ & Yes & Yes & Yes & Yes & No & No & No & No \\
\hline$\%$ CAD & CBD & 0 & 0 & 0 & 30 & 30 & 12 & CBD \\
\hline$\%$ Women & CBD & 81 & 80 & 87 & 83 & 82 & 88 & 77 \\
\hline$\%$ DM & $\mathrm{CBD}$ & 27 & 25 & 27 & 20 & 32 & 29 & 21 \\
\hline $\begin{array}{l}\text { Follow-up } \\
\text { (months) }\end{array}$ & $28 \pm 18$ & $21 \pm 10$ & $24 \pm 10$ & $24 \pm 13$ & $27 \pm 13$ & $29 \pm 12$ & $28 \pm 20$ & $14 \pm 7$ \\
\hline $\begin{array}{l}\text { CD/NFMI } \\
(\%)\end{array}$ & 3 & 0 & 0 & 0 & 1.4 & 11 & 12 & 2 \\
\hline Revasc (\%) & CBD & 6.0 & 9 & 14 & 2.8 & 14 & 10 & 12 \\
\hline
\end{tabular}

Dipy, Dipyridamole; Adeno, adenosine; $C B D$, could not be determined; Rega, regadenoson; $C A D$, coronary artery disease; $D M$, diabetes mellitus; Revasc, revascularization; CD, cardiac death; NFMI, nonfatal myocardial infarction.

* Presented as abstract.

otherwise deemed to be at increased risk either clinically or by other non-perfusion parameters (i.e., transient ischemic dilation, left ventricular dysfunction, etc.), to warrant referral to invasive evaluation, even though MPI was otherwise normal. Of all patients who went on to catheterization, 24\% had ischemic ECG changes in the setting of normal perfusion. In contrast, in the prognostic cohort, only 248 patients (7\%) of the 3,566 patients had ST segment depression on the stress ECG. Of these 248, $130(52 \%)$ had normal MPI, and as such comprised a significant majority in this cohort. Potential reasons for the high rate of CAD in those patients referred for angiography, and a low event rate the prognostic cohort, in comparison to prior studies, may also be related to patient selection (i.e., exclusion of CABG and prior MI). Also, the resting ECG may also explain potential differences in the various study findings. Exclusion criteria such as baseline ECG abnormalities, evidence of left ventricular hypertrophy, and digoxin use, varies considerably among studies. Studies that include these baseline abnormalities will tend to find more falsepositive results, while those that exclude these will be more apt to see these changes reflect worse outcome. Nonetheless, the findings of the present study strongly suggest that ischemic ECG changes during vasodilator stress should not be a "knee-jerk" indication for coronary angiography in all patients.

All studies of vasodilator stress ECG changes and normal MPI have been limited by the fact that this constellation of finding occurs uncommonly, and as such patient numbers are quite low, and subsequent event rates are even lower. Outside of a prospective study, how can we reconcile the differences in the published studies examining the clinical significance of vasodilator stress-induced ST-segment depression associated with normal MPI? Perhaps, we must consider that the prognostic value of vasodilator stress-induced ECG changes may vary according to gender, history of CAD, prior MI or revascularization, etc. Non-epicardial microvascular disease, the influence of estrogen, the presence of collateralized occluded arteries, as well as the concept of "balanced ischemia," have all been considered as possible contributors to this phenomenon. As such, it remains possible that this unique finding may vary depending on the patient population studied.

When considering the differences in the study design and notable disparate findings of the published studies, some potential paradigms can be posited. Based on the findings of the current study by Azemi and coworkers, in patients with no history of MI or prior CABG, and in those with a lower pre-test likelihood of $\mathrm{CAD}$, the finding of ST-segment depression with vasodilator stress in concert with normal MPI is highly likely to be a "false positive" finding. Accordingly, in the absence of any other concerning clinical or non-perfusion parameters, invasive evaluation should be deferred given the anticipated lower incidence of significant $\mathrm{CAD}$, given the quite favorable prognosis demonstrated in these patients in the current study. However, on the basis of previous studies, when ischemic ECG changes develop during vasodilator stress in patients with known $\mathrm{CAD}$ and/or prior MI or revascularization, and perhaps 
in diabetics or other patient populations who might be expected to have an increased incidence of multi-vessel coronary artery disease, consideration should be given to the potential for a "false negative" MPI when interpreting these discordant results. As such, when faced with the finding of ECG changes during vasodilator stress, based on the findings of Azemi and colleagues, ST-segment depression may be less cause for anxiety in most, but perhaps not all, patients in whom this unique and controversial finding occurs.

\section{References}

1. Einthoven W. Le telecardiogramme. Arch Int Physiol 1906;4:132.

2. Kushner FG, Hand M, Smith SC Jr, King SB III, Anderson JL, Antman EM, et al. 2009 focused updates: ACC/AHA guidelines for the management of patients with ST-elevation myocardial infarction (updating the 2004 guideline and 2007 focused update) and ACC/AHA/SCAI guidelines on percutaneous coronary intervention (updating the 2005 guideline and 2007 focused update) a report of the American College of Cardiology Foundation/American Heart Association Task Force on Practice Guidelines. J Am Coll Cardiol 2009;54:2205-41.

3. Iskandrian AS, Chae SC, Heo J, Stanberry CD, Wasserleben V, Cave V. Independent and incremental prognostic value of exercise single-photon emission computed tomographic (SPECT) thallium imaging in coronary artery disease. J Am Coll Cardiol 1993;22: 665-70.

4. Gibbons RJ, Hodge DO, Berman DS, Akinboboye OO, Heo J, Hachamovitch R, et al. Long-term outcome of patients with intermediate risk exercise electrocradiograms who do not have myocardial perfusion defects on radionuclide imaging. Circulation 1999;100:2140-5.
5. Hachamovitch R, Hayes SW, Friedman JD, Cohen I, Berman DS. A prognostic score for prediction of cardiac mortality risk after adenosine stress myocardial perfusion scintigraphy. J Am Coll Cardiol 2005;45:722-9.

6. Abbott B, Afshar M, Berger A, Wackers F. Prognostic significance of ischemic electrocardiographic changes during adenosine infusion in patients with normal myocardial perfusion imaging. J Nucl Cardiol 2003;10:9-16.

7. Klodas E, Miller TD, Christian TF, Hodge DO, Gibbons RJ. Prognostic significance of ischemic electrocardiographic changes during vasodilator stress testing in patients with normal SPECT images. J Nucl Cardiol 2003;10:4-8.

8. Hage F, Dubovsky E, Jaekyeong H, Iskandrian A. Outcome of patients with adenosine-induced ST-segment depression but with normal perfusion on tomographic imaging. Am J Cardiol 2006;98: 1009-11.

9. Sharma J, Roncari C, Giedd KN, Fox JT, Kanei Y. Patients with adenosine-induced ST-segment depressions and normal myocardial perfusion imaging: Cardiac outcomes at 24 months. J Nucl Cardiol 2010;17:874-80.

10. Azemi T, Mridula R, Parwani P, Baghdasarian S, Kazi F, Ahlberg AW, Cyr G, Katten D, O'Sullivan D, Fram D, Heller GC. Electrocardiographic changes during vasodilator SPECT myocardial perfusion imaging: Does it affect diagnosis or prognosis? doi: 10.1007/s12350-011-9457-x

11. Chow BJW, Wong JW, Yoshinaga K, Ruddy TD, Williams K, deKemp RA, et al. Prognostic significance of dipyridamoleinduced ST depression in patients with normal ${ }^{82} \mathrm{Rb}$ PET myocardial perfusion imaging. J Nucl Med 2005;46:1095-101.

12. Hage FG, Heo JH, Iskandrian AE. Adenosine-induced ST segment depression with normal perfusion. Cardiol J 2009;2:121-6.

13. Uthamalingam S, Gurm GS, Ahmado I, Sidhu M, Flynn J. Outcome of patients with Regadenoson-induced ST-segment depression but with normal perfusion on single photon emission computed tomography. J Nucl Cardiol 2011;18:4. (9.25 abstract). 